\title{
Contextual encoding and recovery from interference in the Brown-Peterson paradigm
}

\author{
DAVID S. GORFEIN and NANCY SCHULZE \\ New College, Sarasota, Florida $\$ 3580$
}

\begin{abstract}
Short-term memory in the Brown-Peterson paradigm has consistently shown enhanced performance on a trial following a long intertrial interval (ITI) as compared to performance in the absence of such an ITI. Whereas the fact of dissipation of interference has been clearly documented, the mechanism of such is not as well understood. The nature of the activity required of the subject during the long ITI was manipulated to assess the hypothesis that the amount of improvement obtained is a function of the contextual change produced during the ITI. The data indicated that such an interpretation is a tenable explanation of release from proactive interference over a long ITI.
\end{abstract}

A number of studies in short-term memory (Loess \& Waugh, 1967; Peterson \& Gentile, 1965) have shown that the buildup of proactive inhibition (PI) in the Brown-Peterson short-term memory paradigm can be retarded by long intertrial intervals (ITI). In a similar fashion, it has been demonstrated that, over a long ITI, release from PI is obtained following a block of relatively massed trials (Gorfein, 1974; Kincaid \& Wickens, 1970):

While the fact of release from PI has been amply documented, the mechanism by which it occurs has not been thoroughly explored. The present study is an outgrowth of our research on the nature of the retrieval cue in memory situations in which the experimenter does not supply a retrieval cue, i.e., studies other than the studies of the paired-associate type. A theoretical view is that, when a subject is called upon to retrieve from memory, he uses the current experimental context (where context is used in the sense that Estes (1950) uses the word "stimulus" in stimulus sampling theory) to probe memory and chooses from memory items that are marked with a context tage similar to the current context. While a great deal of attention has been paid recently to the difference between the nominal and effective stimulus in the human learning situation, and in particular to the stimulus-as-coded, aside from a handful of investigators (Bilodeau \& Schlosberg, 1951; Dallett \& Wilcox, 1968; Falkenberg, 1972; Strand, 1970), the full import of the stimulus situation has been ignored; and all of the work has concentrated on the nominal stimulus. This is in striking contrast to the animal learning literature. In that area, stimulus sampling theory has consistently included the full environmental situation, including such factors as

Presented at the Annual Meeting of the Psychonomic Society, Boston, 1974. Reprints may be obtained from Dr. David S. Gorfein, Chairman, Psychology Department, Adelphi University, Garden City, Long Island, New York 11530. proprioceptive cues, kinesthetic sensations, and visceral sensations. In the realm of animal learning, the stimulus sampling theory has been a powerful tool in analysis.

It is the view of the present investigators that while the nominal stimulus as encoded will have a dominant effect in some learning situations-in particular, paired-associate learning-too little attention has been paid to other contextual stimuli. Recently Alexy and Gorfein (Note 1) have used this model to account for recency effects in free-recall situations. It is hypothesized that the reason release occurs following a long ITI is that the contextual fluctuations over the ITI result in a strikingly different encoding cue for the item following the long ITI. This prevents response competition at retrieval. In the present study, we manipulate the activity in which the subject engages during the long intertrial interval to see if differential amounts of release can be obtained as a function of how much the intertrial activity resembles the normal trial activity. Four ITI activities were employed. Since there was no a priori way of knowing what a similar activity would mean, we simply chose a variety of activities and made our best judgment as to the predicted direction of the effect. We anticipated that a signal detection activity during a long ITI would be most dissimilar to the normal experimental context, as the experimental context was primarily a memory and visual task whereas a signal detection task is primarily a perceptual and auditory task. An unfilled rest period, while similar to the rest periods following each trial, was expected to produce a fair amount of release since the ITI was of sufficient duration to allow the subject's attention to wander and presumably produce a fluctuation in the stimuli that the subject would sample at the start of the next trial.

A number shadowing task during the ITI was chosen to be similar to the retention interval activity and was expected to preserve context to a fair degree. Finally, a dummy trial identical in structure to a normal trial, except that no memory load was placed 
on the subject, was employed. It was anticipated that this would produce the smallest amount of release.

\section{METHOD}

\section{Materials}

Twenty-four blocks of six categorized words were drawn from the Battig and Montague (1969) norms. Four words were drawn from other categories to serve as practice items.

\section{Procedure}

The experimental procedure used a modification of Bennett's (1975) forced choice procedure and Gorfein and Jacobson's (1973) recognition latency procedure. Items to be remembered were single words. In lieu of a recall procedure, the subject was presented with two words (one above the other) - the current item, and the immediately prior item (the item from the last previous trial)-and asked to choose which was the current item and indicate the choice by pressing a key marked "top" or "bottom." The dependent variable was response latency. Subjects were instructed to respond as fast as they could, consistent with being $100 \%$ correct.

Items were visually presented by a Kodak-Carousel projector controlled by Hunter Timers. Subjects were tested for 148 trials, 4 practice trials followed immediately by 24 blocks of 6 trials where each trial block came from a different semantic category. A trial consisted of a READY slide for $2.0 \mathrm{sec}$, the item for $1.1 \mathrm{sec}$, an 8.7 -sec period of digit shadowing at a rate of $3.5 / \mathrm{sec}$, a pair of words one below the other for $4.2 \mathrm{sec}$, and a REST slide for $4.0 \mathrm{sec}$

In eight of the blocks, a long ITI $(44 \mathrm{sec})$ was inserted between Items (Trials) 3 and 4 . In eight blocks, a long ITI was inserted between Items 4 and 5 . Eight blocks had no long ITI and served as control blocks. Assignment of blocks to release condition, item order within blocks, and whether the correct probe is on top or bottom for the forced choice was balanced across subjects.

Four manipulations of the ITI activity were performed as a between subject variable:

Rest: ITI unfilled interval.

Shadow: Subject shadowed numbers as he did in retention intervals.

Signal detection: Subject performed 11 4-sec forced-choice auditory signal detection trials.

Dummy: Trial proceeded as usual; but no TBRI was given, only word "Top" or "Bottom" which was repeated in the recognition period with the subject instructed to press the appropriate key. Dummy procedure was for two trials.

\section{Subjects}

Forty New College students were paid to serve in this experiment. Subjects were assigned to experimental condition in the order they came to the laboratory, with the conditions counterbalanced.

\section{RESULTS AND DISCUSSION}

Reaction time (RT) data were collected from onset of probe to response. Since there were substantial individual differences in $\mathrm{RT}$, mean $\mathrm{RT}$ for each subject was converted to a percentage of his Trial 1 mean RT averaged across blocks, so that all subjects and conditions could be related to each other.

Figure 1 shows the results. As can be seen, in all conditions there was a significant increase in RT as a function of trial within block for the control sets. The overall effect of PI release is significant, although the dummy trial group failed to show PI release when the ITI was inserted after Trial 3.Analysis of the release data points (shown as circled unconnected points on the figure) showed a significant effect of the ITI manipulation $F(3,44)=4.38, p<.01$. A Scheffé analysis of the data indicates that the difference is due to the contrast of the dummy and shadowing vs. rest and signal detection. The direction of the difference is as we predicted on the basis of the contextual change model.

It is our belief that this study demonstrates the importance of associationist principles in understanding memory processes. It is conceivable that a wide variety of short-term changes over time may be due to contextual fluctuation in the stimulus sampling sense. Further work is underway to explore the power of contextual fluctuation as an explanatory mechanism in memory studies.

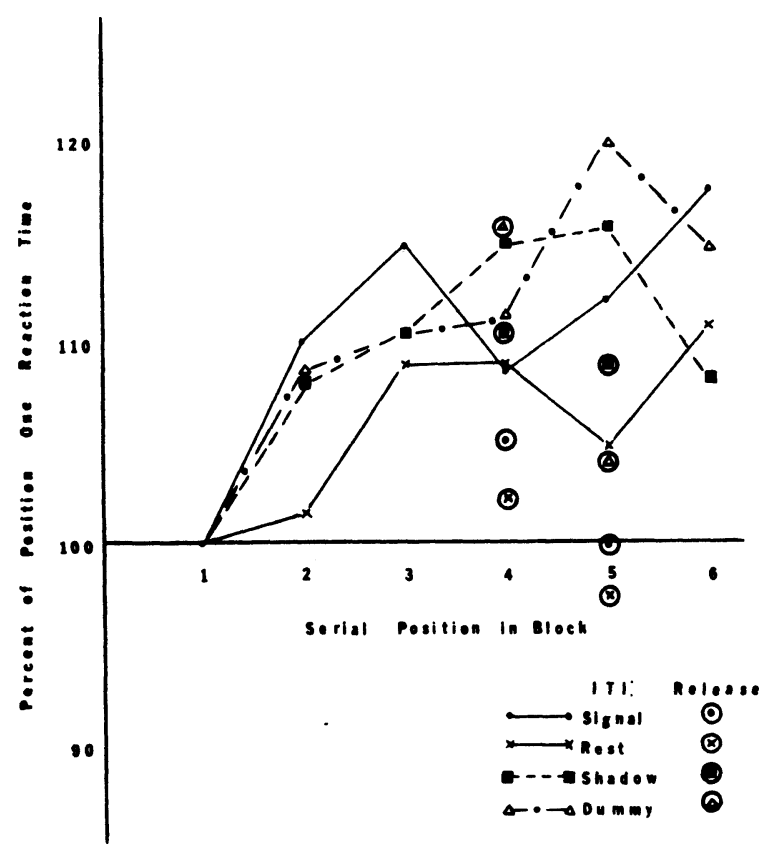

Figure 1. Release from PI over a long ITI as a function of the ITI activity.

\section{REFERENCE NOTE}

1. Alexy, M., \& Gorfein, D. S. A contextual interpretation of recency-sensitive retrieval processes in long-term free recall. Paper read at The Meeting of The Midwestern Psychological Association, Chicago, 1973.

\section{REFERENCES}

Battig, W. F., \& Montague, W. E. Category norms for verbal items in 56 categories: A replication and extension of the Connecticut category norms. Journal of Experimental Psychology Monograph, 1969, 80 (3, Pt. 2).

BenNetT, R. W. Proactive interference in short-term memory: Fundamental forgetting processes. Journal of Verbal Learning and Verbal Behavior, 1975, 14, 123-144.

Bilodeau, I. M., \& Schlosberg, H. Similarity in stimulating conditions as variable in retroactive inhibition. Journal of Experimental Psychology, 1951, 41, 199-204. 
Dallett, K., \& Wilcox, S. J. Contextual stimuli and proactive inhibition. Journal of Experimental Psychology, 1968, 78, 475-480.

Estes, W. K. Towards a statistical theory of learning. Psychological Review, 1950, 57, 94-107.

FALKENBERG, P. R. Recall improves in short-term memory the more recall context resembles learning context. Journal of Experimental Psychology, 1972, 95, 39-47.

Gorfein, D. S. Time release from proactive inhibition is a function of amount of proactive inhibition present. Journal of Experimental Psychology, 1974, 103, 201-203.

Gorfein, D. S., \& Jacobson, D. E. Memory search in a BrownPeterson short-term memory paradigm. Journal of Experimental Psychology, 1973, 99, 82-87.
Kincaid, J. P., \& Wickens, D. D. Temporal gradient of release from proactive inhibition. Journal of Experimental Psychology, 1970, 86, 313-316.

Loess, H., \& WAUGH, N. C. Short-term memory and intertrial intervals. Journal of Verbal Learning and Verbal Behavior, 1967, $6,455-460$.

Peterson, L. R., \& Gentile, A. Proactive interference as a function of time between tests. Joumal of Experimental Psychology, 1965, 70, 473-478.

Strand, B. A. Change of context and retroactive inhibition. Journal of Verbal Learning and Verbal Behavior, 1970, 9, 202-206.

(Received for publication August 4, 1975.) 